\title{
Executive Functioning and Figurative Language Comprehension in Learning Disabilities
}

\author{
Saied Bishara ${ }^{1, *}$ \& Shani Kaplan ${ }^{2}$ \\ ${ }^{1}$ Special Education Department, Beit Berl College and Open University, Ra'anana, Israel \\ ${ }^{2}$ Didactic Diagnostic and Expert on Learning Disabilities and Remedial, Israel \\ *Correspondence: Special Education Department, Beit Berl College and Open University, Ra'anana, Israel. E-mail: \\ saiedbs@gmail.com
}

Received: January 5, 2016

Accepted: February 13, $2016 \quad$ Online Published: March 28, 2016

doi:10.5430/wje.v6n2p20

URL: http://dx.doi.org/10.5430/wje.v6n2p20

\begin{abstract}
The goal of the research was to examine executive functioning and figurative language comprehension among students with learning disabilities as compared to students without learning disabilities. As part of the research, we examined 20 students with learning disabilities and 21 students with no learning disabilities, both groups of students attend $7^{\text {th }}$ and $8^{\text {th }}$ grade (ages 12-13). The participants were selected using: Glantz Abstract Verbal Thinking Test of cognitive skills (2010), reading words with and without visual punctuation(Note 1) as well as a set of dummy words (Hadad, 2010). The level of executive functioning was evaluated using three types of assessment tools: a multiple meaning word questionnaire, semantic fluency and phonetic fluency tests. The level of figurative speech was evaluated using four assessment tools: idioms, colloquial expression, metaphor questionnaire and a pictorial metaphor test.

The development of language proficiency along with enhanced use of aural and visual metaphors among children with learning disabilities, may contribute to improving the ability to plan, reinforce flexibility, bolster working memory and establish self monitor fluency; this in turn, builds up creative and abstract thinking as well as the ability to understand and produce a metaphor. These findings and conclusions have implications on a variety of pedagogical experiences including the reduction in school dropout rate, advancement of student achievements thereby bolstering academic self esteem.
\end{abstract}

Keywords: executive functioning; figurative language; students with learning disabilities

\section{Introduction}

The population of students with learning disabilities is characterized by a variety of functional challenges (Kavale \& Forness, 1996). In this research we chose to focus on two of them: executive functioning level and figurative language comprehension. Children with learning disabilities struggle with both, executive functioning (Reiter, Tucha \&Lange, 2005) and figurative language comprehension (Lee \& Kamhi, 1990).

Executive functioning has a specific role in the cognitive and emotional development of a normative child (Monetten, Birgras \& Guay, 2011), these executive functioning include the ability to self monitor, working memory, flexibility, planning, fluency and concept perception (Monetten, Bigras, \& Guay, 2011).

Figurative language is defined as "the use and non literal comprehension of spoken language” (Ackerman, 1982). It includes metaphors, idioms and more (Nippold, 1988). The ability to understand and produce a metaphor (figurative language) reflects the cognitive level of an individual, his level of creativity and capacity for abstract thinking. Since this ability improves over the years, indicants of metaphorical thinking ability also provide an indication as to conceptual development and appropriate linguistic abilities of children during schooling years (Lee \& Kamhi, 1990).

In this article we are going to use the term "learning disabilities" to describe specific learning difficulties with reading defined by common terminology in use by the ministry of education (2004) and that is based on NJCLD (National Joint Committee on Learning Disabilities) definition (1994). The article does not use the term "specific learning disorder" as defined by DSM-5 (Diagnostic and Statistical Manual of Mental Disorder) because the research is quasi experimental and does not meet DSM-5 main criteria for an assessment process that is based on a response 
to focused intervention with the specific difficulty, and the tracking of said difficulty for at least six months.

This research looks to contribute to the expansion of professional and academic knowledge in the area of executive functioning, figurative language comprehension, and their correlation as they relate to students with learning disabilities compared to students with no learning disabilities. There is a gap in current research of the subject. The findings of this research may shed some light on and facilitate a deeper understanding of students who are having difficulties with reading comprehension. As a result, it may become possible to plan the role of an educational counselor more efficiently and better coordinate her efforts with the various agencies responding to the needs of these students. Finally, it may become possible to offer an educational plan and recommendations for practical applications that will lead to improved reading comprehension of students with learning disabilities and therefore to bolstering their personal and academic performance.

\section{Learning Disability, Definitions and Characteristics}

The term "learning disability" has developed since it was first introduced by Kirk (1963). The common element of the various definitions of this term is the perception of learning disabled children as having various difficulties originating in a dysfunction of the central nervous system. Neurological dysfunction is defined as a specific group of dysfunctional patterns of behavior, making it different than a physiological or anatomical injury of tissue defined as "brain damage" (Birch, 1981). A learning disability, as defined by the ministry of education (Ministry of Education, 2004) is based on NJCLD definition (1994), and includes two conditions for assessment:

a) There is a significant and ongoing learning gap between the academic achievements of the student and what is appropriate for his age and grade level.

b) There is a significant gap between the academic and intellectual achievements of the students as indicated by objective IQ tests.

In the 2013 publication of the statistical assessment guide of mental disorders known as DSM - 5, significant changes were made in the definition of the term "learning disability" and to its assessment criteria (Tannock, 2013). The term "Learning Disability" was substituted with the term "Specific Learning Disorder" and from that point on it refers to three distinct academic areas: 1 . Specific learning disorder with a deficiency is reading; 2 . Specific learning disorder affecting expressive writing ability; 3. Specific learning disorder with deficiency in Mathematics.

According to DSM - 5 the assessment of a specific learning disorder with a reading deficiency is based on the coding of the following sub-proficiencies: a. accuracy in reading words; b. reading pace and fluency; 3 . reading comprehension.

A learning disorder in this area can be expressed in lack of accuracy, slow pace or intense effort in attempting to read words. For example, sounding words incorrectly, slowly or hesitantly; guessing the meaning of words often, difficulty in sounding or pronouncing words. The disorder can also be expressed by a difficulty in reading comprehension. For example, the reading of the words is accurate but there is a difficulty in understanding the sequence, the relationships, the natural conclusions or deeper meaning of the content being read (Tannock, 2013).

It looks as though the significant and central change in the DSM - 5 definitions is the focus on specificity. It is made sufficiently clear from the new definition's title: "Specific Learning Disorder". In other words, it's no longer sufficient to generalize a learning disorder; instead, it is now necessary to specifically define the disorder based on the detailed code provided.

The demand for specificity reflects the progress made in the area of learning disabilities research which in line with DSM-5, also refers to specific learning disabilities. A specific definition of a disability allows for a focused intervention.

Another aspect of this change is the distancing from the gap model; while in the two previous publications DSM (1994; 2000) the clinical characterization was supported by the gap model, the current definition does not make a mention of it at all. The guide does not specify the correct assessment approach, but it does consider the introduction of the Response to Intervention model which received a formal recognition as an official assessment approach in 2004 (Berkeley et al., 2009). In other words, RTI is part of the criteria for assessment but it is not completely sufficient. It is still necessary to perform an evaluation of the gap between the expected ability based on age, and the actual assessed academic proficiency as a direct result of the disability. The DSM - 5 emphasizes that the existence of sensory and neurological deficiencies is completely distinct from a learning disorder. 


\section{Executive Functioning}

"Executive Functioning" is a term that describes a set of mental processes that facilitates the connection between past experiences and present actions. The performance ability of executive functioning manifests itself in actions that involve planning, organization, use of strategies and mental flexibility, paying attention and memorizing details (National Center for Learning Disabilities, 2005). These processes also include self-monitoring, working memory, flexibility, fluency and concept perception. A deficiency in any of these factors is much more apparent in those suffering from ADD (Attention Deficit Disorder), ADHD (Attention Deficit Hyperactivity Disorder), Dyslexia, and dyscalculia and to a certain extent depression, anxiety and communicative disorder such as Asperger and sleeping disorders (Monetten, Bigras, \& Guay, 2011).

Those with deficiencies in executive functioning have a difficult time planning, organizing and managing time and space. They have a weakened working memory, a critical tool that guides our actions. As with other expressions of learning disabilities, a deficiency in executive functioning can be hereditary. Signs of it can be observed at any age although they are much clearer in children in the first years of elementary school. The expectation of completing homework independently may reveal early signs of difficulty in this area (National Center for Learning Disabilities, 2005).

One of the parameters used to evaluate executive functioning is cognitive flexibility (Catroppa \& Anderson, 2005). Cognitive flexibility is called for when completing assignments that require search strategies and mental copying mechanisms. For example, in a phonological fluency assignment, the participant is asked to recall as many words as possible that begin with a certain sound. To complete this assignment, the participant has to activate search strategies and mental flexibility mechanisms. In addition, with this specific assignment, the participant is not able to rely on familiar conceptual categories; so a great deal of mental flexibility is called for (Kave, Avraham, Kukulansky-Segal \& Herzberg, 2007).

Children with learning disabilities have a difficult time performing actions that rely on executive functioning and therefore cannot reach the level expected of their peers in areas such as: language and aural proficiency, time management, mental flexibility and the selection of relevant sensory information.

\section{Figurative Language}

"Figurative Language" is defined as "use and understanding of non-literal aspects of spoken language" (Ackerman, 1982); it includes metaphors, idioms and more (Nippold, 1988). Figurative language is frequent in the daily use of spoken language, that's why it has an important impact on general language comprehension abilities. Figurative language comprehension starts developing at a very early age. It was found that 7 year old children were able to identify the meaning of figurative idioms when put in a context with sufficient information (Ackerman, 1982). With age, figurative language comprehension improves (Nippold, 1988). As with the acquisition of a single word, the meaning of idioms is acquired through exposure to the expression in different contexts. The comprehension of idioms involves analytical action in which an individual must first conclude the meaning of the expression in the given context and then deduce the overall figurative meaning of the expression (Owens, 1992). Although figurative language comprehension can be found among children, this comprehension gets progressively more sophisticated during childhood, adolescence and adulthood (Nippold, 1988).

Difficulties in using pragmatic (figurative) language are common among several clinical populations such as those with damaged right hemisphere, autism and brain damage (Martin \& McDonald, 2003). A research conducted among schizophrenia patients to examine the connection between pragmatic difficulties and deficiency in executive functioning, concluded that schizophrenia patients showed pragmatic difficulties and pronounced deficiency in executive functioning such as lack of flexibility (Champagne-lavau \& Stip, 2010).

Similarly, research among patients with autism found a link between deficiency in executive functioning and use of pragmatic language (Geurts, Broeders \& Nieuwland, 2009). The link was found among patients with autism and schizophrenia as well as patients with damaged right hemisphere. It was also found that deficiencies in ToM(Note 2) (Theory of Mind)along with deficient executive functioning are best at predicting different patterns in deficient use of pragmatics (Champagne-Lavau \& Joanette, 2009).

\section{The Link between Executive Functioning and Figurative Language}

Research found a link between executive functioning and pragmatics among various populations. Pragmatics is the ability to understand and produce a communicative step and also includes one's knowledge regarding 'social 
distance', social status between people in conversation, cultural knowledge such as manners, literal as well as implied lexical knowledge such as figurative language (Kasper, 1997).

Mental flexibility, among other things, is at the base of figurative language comprehension. The ability to understand and produce a metaphor reflects one's abstract and creative ability (Martindale, 1999). Mental flexibility is considered to be one of the characteristics of an individual's creative ability.

Those with a highly developed creative ability also have the ability to change their mental state in order to meet the demands of a current assignment (Martindale, 1999).

To fully comprehend figurative language requires creativity and mental flexibility that enables mental navigation outside literal lexical context towards additional meaning. Moreover, figurative language comprehension reflects the ability to reach out and locate higher order lexical meaning and the discernment of this meaning as being more informative than the narrower literal meaning. It requires abstract thinking, the kind that makes it possible to understand that a certain literal interpretation to language is less appropriate than the symbolic interpretation, the one that point to similarities between situations. (Yang, Fuller, Khodaparast \& Krawczyk, 2010)

Specter (1996) relates the ability to understand homophones to figurative language, while Kave (2006) relates this proficiency to executive functioning. "Homophones" assignment measures the ability to navigate between various verbal perceptions. Therefore, when a participant is asked to produce the largest number of meanings to an out of context auditory target word, she is asked to navigate outside the common meaning stimuli and into other concepts linked to the stimuli. This process requires control and mental flexibility that are related to executive functioning (Kave, 2006). It is possible therefore to see a link between the figurative language characteristics and basic characteristics of executive functioning.

\section{Figurative Language Comprehension among Children with Learning Disabilities}

In 1967 Johnson \& Myklebust have already distinguished between "Verbal Learning Disability" and "Non-verbal Learning Disability" even though the distinction was not empirically tested by them. Rourke (1988) supported this division after having conducted several researches since the 70s' and then went on to classify the learning disabilities into "verbal learning disability" and "non-verbal learning disability". According to these researches, children with "non-verbal learning disability" have experienced difficulty with pragmatic language when compared to children with "verbal learning disability", most of whom do not experience the same difficulty (Rourke \& Del Dotto, 1994, Stone \& May, 2002).

In research conducted among children with learning disability and language difficulty, it was found that normative students were significantly more successful interpreting metaphors than students with disability (Lee \& Kamhi, 1990). Additionally, understanding pragmatic meaning like figurative language was found to be an especially sensitive indicator of abstract thinking among children with language and learning disability (Yang, Fukker, Khodaparast \& Krawczyk, 2010).

\section{Executive Functioning Among Children with Learning Disabilities}

In research literature, a link was found between executive functioning and learning disability at the neurological level (Denckla, 1994). This link is important because the system of executive functioning affects organization, planning and coordination of different personal systems. That is why in many cases where a learning disability exists; there is also a deficiency in the executive system (Stone \& May, 2002).

The same literature also cites that children with a learning disability in reading exhibit deficiency in a wide variety of executive functioning (Reiter, Tucha \& Lange, 2004).

To summarize, figurative language comprehension is an important component of language comprehension and understanding the world around us (Spector, 1996). The components of figurative language include abstract words, idioms, similes, metaphors and fables. This comprehension is affected by variables that are linked to executive functioning. Among children with learning disabilities, we observe developmental difficulties in the areas of figurative language and executive functioning. The current research goal is to examine the level of executive functioning, figurative language comprehension and the correlation between them among children with learning disabilities compared to children with no learning disabilities. 


\section{The Research Assumptions Are:}

1. There will be a distinct difference in executive functioning between children with learning disabilities and children with no learning disabilities. The level of executive functioning of participants with learning disabilities will be lower than the level of executive functioning of participants without learning disabilities.

2. There will be a distinct difference between children with learning disabilities and children with no learning disabilities in their figurative language comprehension. The comprehension of participants with learning disabilities will be lower than that of the participants without learning disabilities.

3. There will be a positive correlation between executive functioning and figurative language comprehension among both research sample groups. The higher the executive functioning, the higher the level of figurative language comprehension.

\section{Method}

\subsection{Participants}

There were 41 participants in the research; $7-8^{\text {th }}$ grade students from schools in the central part of the country; 33 boys (80.5\%) and 8 girls (19.5\%). The age range of the students tested varied between 12 to 13 years old (average of 12.3 years old with a 0.45 standard deviation). The students were selected by researchers using appropriate tests and were divided into two groups: the test group included 20 students with learning disabilities (average age 12.4, S.D. 0.5 ), and the control group included 21 students without learning disabilities (average age 12.14, S.D. - 0.36).

\subsection{Research Tools}

\section{a. Screening Tests: Learning Disabilities}

During the first stage, the participants were given screening tests to determine their verbal age using Glantz Abstract Verbal Thinking Test, synonymous and metonymy questionnaires (Glantz, 2010). The tests goal was to rule out the influence of the confounding variable "verbal age", and therefore incongruence between the level of verbal performance of the participants and the level consistent with their chronological age.

Participants that did not pass the screening tests in each of the aforementioned questionnaires in accordance with their chronological age were disqualified from participating.

\section{b. Selective Tests: Learning Disabilities and Normative}

In order to classify the participants into groups of students with learning disabilities and groups with no learning disabilities, reading tests were conducted: words with visual punctuation, no visual punctuation and dummy words (Hadas, 2010). Speed and accuracy of reading were also tested. The speed of reading was tested according to the number of words a participant read correctly during 45 seconds. The accuracy was tested counting the total number of words the participant read correctly out of the total number of words on the list.

\subsection{Executive Functioning Tests}

Each research participant was given three executive functioning tests: multiple meaning words, semantic and phonetic fluency.

a. Multiple Meaning Words Questionnaire:

This questionnaire consists of 20 sentences, each ending with a homophone. (e.g. "They can write/right”) or heterophony (e.g. "they were looking for the root/route"). The participant was asked to say all the possibilities she can recall while reading the last word in the sentence (Hadad, 2010)

\section{b. Semantic Fluency Test:}

A test designed to examine executive functioning such as fluency and mental flexibility. The participant is asked to say as many words as possible within the span of one minute in the following semantic categories: fruits and vegetables, animals and vehicles. The answers are listed and coded based on the number of items recalled in each category (Hadas, 2010).

\section{c. Phonetic Fluency Test:}

A test designed to examine executive functioning such as fluency and mental flexibility The participant is asked to say as many words as possible that begin with the Hebrew letters that are equivalent to ' $b$ ', ' $\mathrm{g}$ ' and 'sh' in English, within the span of one minute The participant can say any word except proper noun. She must use different words 
each time and not the same word with a different ending, (e.g. banana/bananas), say the root of verbs only and no prepositions (e.g. 'to the bench', 'on the ground'). The answers are listed and coded according to the number of items recalled in each category and points are awarded to the correct answers only (Hadas, 2010).

\subsection{Figurative Language Comprehension Tests}

Each participant was given four tests to evaluate the level of figurative language comprehension: idioms, expressions, verbal and pictorial metaphors.

a. Idioms Questionnaire: this questionnaire consists of 20 idioms and four multiple choice answers that include the correct answer, erroneous literal answer, a literal detractor and an out of context answer. The participant is asked to circle the answer that is closest to the meaning of the sentence as a whole. Example: "He has come up empty handed" (Mashal, 2005).

b. Expressions Questionnaire: this questionnaire consists of 20 expressions common in the Hebrew Language and four multiple choice answers that include the correct answer, erroneous literal answer, a literal detractor and an out of context answer. The participant is asked to circle the answer that is closest to the meaning of the sentence as a whole. Example: "I'm not sold on this". The questionnaire also includes expressions of exaggeration: "Shira saw this movie a million times”.

\section{c. Metaphor Questionnaire}

This questionnaire consists of 30 expressions that include new metaphors, familiar metaphors and meaningless expressions. Each expression has four multiple choice answers and the participant has to choose the correct one. One of the answers always includes the option: "this expression is meaningless" (Mashal, 2005)

d. Pictorial Metaphor Test: (Kogan, Connor, Gross \& Fava, 1980): The test was modified to fit the current research and included 16 pairs of pictures with three types of metaphoric associations: a conceptual association, visual-configurative association (having to do with visual characteristics) and effective association (emotional). The pictures were displayed on a personal computer. The answers were listed and coded for a final score between 0-2: 0 score - was not able to find metaphoric association between the pictures; 1 score - was not able to find a metaphoric association independently but was able to understand the connection after intervention; 2 score - was able to find metaphoric association in the pictures without intervention. The maximum score for the test is 32 .

\subsection{Procedure}

The tests were administrated by researchers at the participants' schools. During the first stage participants took the screening test designed to determine their verbal age using Glantz Abstract Verbal Thinking Test, synonymous and metonymy questionnaires (Glantz, 2010). Participants that did not pass the screening tests in each of the aforementioned questionnaires in accordance with their chronological age, were disqualified from participating.

During the second phase, participants were evaluated for speed and accuracy of reading (Hadad, 2010), using a test that measures the reading pace of words with visual punctuation, words with no visual punctuation and dummy words while participants read accurately for 45 seconds.

Next, the participants responded to a series of tests designed to evaluate executive functioning (three tests: multiple meaning words, semantic and phonetic fluency), and tests to evaluate figurative language comprehension (four tests: idiom and expression comprehension, verbal and pictorial metaphors). It is important to note that except for the initial screening tests, the rest of the tests were given randomly

\section{Findings}

As part of the preliminary analysis, the participants were divided into two groups according to the level of their achievements in the reading tests given as part of the research process. Table 1 presents the averages, standard deviance and $t$ values of the reading test scores by research group. According to these findings, among both groups, with learning disability and without, the highest average was observed in reading words without visual punctuation, then in reading words with visual punctuation and finally in reading dummy words. 
Table 1. Averages, Standard Deviations and t Values in Reading Tests by Research Groups

\begin{tabular}{llllll}
\hline & Without LD (N=21) & LD (N=20) & \\
\hline & M & SD & M & SD & t(39) \\
\hline Reading with visual punctuation & 56.30 & 2.76 & 34.50 & 10.30 & $9.36^{* * *}$ \\
Reading with no visual punctuation & 68.95 & 15.16 & 46.45 & 14.98 & $4.78^{* * *}$ \\
Dummy Words & 18.62 & 1.56 & 8.40 & 3.51 & 12.15 \\
\hline
\end{tabular}

${ }^{*} \mathrm{p}<0.05, * * \mathrm{p}<0.01, * * * \mathrm{p}<0.001$

\subsection{Comparing Executive Functioning in Research Groups}

In order to determine whether there is a difference in executive functioning between students with learning disabilities and students with no learning disabilities, a t test for independent samples was conducted. Table 2 presents the averages, standard deviation and t values of executive functioning by research group.

The analysis finds in accordance with the research assumption: that the average executive functioning of students with learning disabilities is significantly lower than that of students with no learning disabilities in all secondary indicants of executive functioning.

Table 2. Averages, Standard Deviation and t Values of Executive Functioning by Research Group

\begin{tabular}{llllll}
\hline & \multicolumn{2}{l}{ No Learning Disabilities } & \multicolumn{2}{l}{ Learning Disabilities } \\
\hline & M & SD & M & SD & t(39) \\
\hline Multiple Meaning Words & 18.9 & 1.22 & 14.4 & 4.12 & $-4.66^{* * *}$ \\
Semantic Fluency & 45.48 & 12.6 & 37.00 & 6.6 & $-2.67 * *$ \\
Phonetic Fluency & 28.62 & 6.00 & 21.2 & 5.86 & $-4.00^{* *}$ \\
\hline
\end{tabular}

${ }^{*} \mathrm{p}<0.05, * * \mathrm{p}<0.01, * * * \mathrm{p}<0.001$

\subsection{Comparing Figurative Language Comprehension between Research Groups}

In order to determine whether there is a difference in figurative language comprehension between students with learning disabilities and students with no learning disabilities, a t test for independent samples was conducted. Table 3 presents the averages, standard deviation and $t$ values of figurative language comprehension by research group. The analysis finds in accordance with the research assumption: that the average figurative language comprehension of students with learning disabilities is significantly lower than that of students with no learning disabilities in all sub-tests evaluating figurative language comprehension.

Table 3. Averages, Standard Deviation and t Values for Figurative Language Comprehension by Research Group

\begin{tabular}{llllll}
\hline & \multicolumn{2}{l}{ No Learning Disabilities } & \multicolumn{3}{l}{ Learning Disabilities } \\
\hline & $\mathbf{M}$ & SD & M & SD & t(39) \\
\hline Idioms & 18.95 & 1.16 & 14.2 & 3.40 & $-5.94^{* * *}$ \\
Expressions & 19.67 & 0.66 & 15.45 & 3.07 & $-6.04^{* * *}$ \\
Verbal Metaphors & 23.95 & 2.46 & 16.00 & 4.95 & $-6.46^{* * *}$ \\
Pictorial Metaphors & 29.57 & 1.86 & 26.15 & 2.45 & $-5.05^{* * *}$ \\
\hline
\end{tabular}

${ }^{*} \mathrm{p}<0.05, * * \mathrm{p}<0.01, * * * \mathrm{p}<0.001$

\subsection{The Link between Executive Functioning and Figurative Language Comprehension}

In order to determine whether there are distinct correlations between executive functioning and figurative language comprehension, Principal Component Analysis (PCA) was applied to the data indicants. The result of the analysis demonstrates a distinct positive correlation between two indicants of executive functioning: multiple meaning words and phonetic fluency, and all four indicants of figurative language comprehension. Additionally, there was a distinct positive correlation between the indicant of semantic fluency and that of metaphors. 
Table 4. Correlations between Executive Functioning and Figurative Language Comprehension

\begin{tabular}{lllll}
\hline Indicants of Executive & \multicolumn{4}{l}{ Indicants of Figurative Language Comprehension } \\
\cline { 2 - 5 } Functioning & Idioms & Expressions & Metaphors & Pictorial Metaphors \\
\hline Multiple Meaning Words & $0.61^{* *}$ & $0.61^{* *}$ & $0.66^{* *}$ & $0.38^{*}$ \\
& $(41)$ & $(41)$ & $(41)$ & $(41)$ \\
Semantic Fluency & 0.29 & 0.30 & $0.32^{*}$ & 0.26 \\
& $(41)$ & $(41)$ & $(41)$ & $(41)$ \\
Phonetic Fluency & $0.43^{* *}$ & $0.51^{* *}$ & $0.51^{* *}$ & $0.47^{* *}$ \\
& $(41)$ & $(41)$ & $(41)$ & $(41)$ \\
\hline
\end{tabular}

${ }^{*} \mathrm{p}<0.05,{ }^{* *} \mathrm{p}<0.01,{ }^{* * *} \mathrm{p}<0.001$

In addition, the correlation between all executive functioning indicants and figurative language comprehension indicants was examined for each research group separately. No significant correlation was found between executive functioning and figurative language comprehension among children with learning disabilities. However, among students with no learning disabilities there was a distinct positive correlation between multiple meaning words and verbal metaphors $(r=0.45 . \mathrm{p}<0.05)$, and between phonetic fluency and verbal metaphors $(\mathrm{r}=0.45, \mathrm{p}<0.05)$.

\section{Discussion and Summary}

The goal of the research was to examine the level of executive functioning, figurative language comprehension and the correlation between them among students with learning disabilities compared to students with no learning disabilities.

\subsection{The Level of Executive Functioning among Students with Learning Disabilities and Students with no Learning Disabilities}

The research demonstrates that the level of executive functioning of students with learning disabilities is lower than that of normative students. In professional literature, a correlation between executive functioning and learning disabilities was found at the neurological level (Denckla, 1994). This correlation is important because the system of executive functioning has an impact on organization, planning and coordination between different systems. That is why; in many cases of learning disability we also find a deficiency in the executive system (Stone \& May, 2002).

A group of learning disabled students is a heterogeneous group and is usually divided into types of disability. In 1967 Johnson \& Myklebust distinguished between "verbal learning disability" and "non-verbal learning disability" even though the distinction was not empirically tested by them. Rourke (1988) supported this distinction as a result of several research projects he conducted starting in the 70s' whereby he classified learning disabilities based on "verbal learning disabilities" and "non-verbal learning disabilities". According to his research, children with non-verbal learning disability had difficulty with pragmatic language compared to children with verbal learning disability, most of which did not demonstrate difficulty in this area (Rourke \& Del Dotto, 1994, Stone \& May, 2002).

On further research it is recommended to conduct selective tests to distinguish between types of learning disabilities. This kind of distinction between types of disability may hone the findings and implications arising from them. In theory, it is possible to examine whether specific disabilities in executive functioning can predict verbal and non verbal learning disability and later, predict language disability in pragmatics.

11.2 Figurative Language Comprehension among Children with Learning Disabilities and Children with no Learning Disabilities

The research findings demonstrate that students with learning disabilities have difficulties with figurative language comprehension compared to normative students. This correlates with research conducted among children with learning disabilities and a language deficiency, there we found that normative students interpreted metaphors more successfully than participants with learning disabilities (Lee \& Kamhi, 1990).

In addition, pragmatic meaning comprehension and figurative language comprehension were found to be particularly sensitive indicants of abstract thinking among children with language and learning disabilities (Yang, Fukker, Khodaparast \& Krawczyk, 2010). A research conducted among high school students found that participants with language disability as compared to normative students had a difficult time with figurative language comprehension that had humorous elements to it. The first had especially difficult time comprehending homophones, words with more than one meaning (Spector, 1990). 
Specter (1996) correlates the ability to understand homophones with figurative language, while Kave (2006) correlates this proficiency with executive functioning. "Homophones" assignment measures the ability to navigate between various verbal perceptions. Therefore, when a participant is asked to produce the largest number of meanings to an out of context auditory target word, she is asked to navigate outside the common meaning stimuli and into other concepts linked to the stimuli. This process requires control and mental flexibility that are related to executive functioning (Kave, 2006). It is possible therefore to see a link between the figurative language characteristics and basic characteristics of executive functioning.

\subsection{Correlation between Executive Functioning and Figurative Language Comprehension}

The findings of the research partially support the existence of this correlation because a distinct connection was found between executive functioning and figurative language comprehension among the general sample. This finding is also in line with Champagne (2009) research which claims that there is a correlation between executive functioning and pragmatic abilities.

Champagne (2009) examined this correlation among patients with schizophrenia and found that among patients exhibiting pragmatic deficiencies there was also deficiency in executive functioning such as mental flexibility and ToM (Theory of Mind).

In the article published by Martin \& McDonald (2003) there are circumstantial explanations to the pragmatic difficulties among different populations but they branch out and tend to contradict each other. Still, they examined different theories designed to explain pragmatic language disabilities and suggested that executive functioning deficiency is one of the factors that may account for deficiency in pragmatic language. Kave (2006) claims that tests conducted to examine mental flexibility reflect one of the most important factors to assessing the level of executive functioning.

That is why, theoretically, it is safe to assume that the correlation between figurative language comprehension and executive functioning can be explained by the factor: mental flexibility (as it is expressed via tests of language fluency, the homophone assignment and other assignment to test figurative language comprehension).

It is also possible there are other variables that connect figurative language comprehension to executive functioning. For example, it is possible that "reading comprehension" is another critical link connecting the two. Research shows a connection between executive functioning and the level of reading fluency and comprehension (Sesma, Mahone, Levine, Eason \& Cutting, 2009, Cutting et al., 2009, De Jong, Van De Voorde, Roeyers, Raymaekers, Allen, Knijff, Rodriguez-Pereira, 2009). Also, reading comprehension is basic and essential to understanding metaphors (Levorato, Nesi \& Cacciari, 2004).

Therefore, in future research it may be wise to add parameters that will evaluate reading comprehension and fluency.

In looking at the correlation between executive functioning and figurative language comprehension in each of the research groups (with LD and with no LD) separately, no distinct correlation was found between the variables in the learning disabilities group. Also, in the group of students with no learning disabilities, only one correlation was found between one indicant of figurative language comprehension (the metaphor test) and two indicants of executive functioning (homophones and phonetic fluency). It is possible that this difference is a result of too small a sample (20 in each group). Therefore in future research, it may be wise to examine this correlation among a larger sample representing the sub-populations of the one examined in this research.

It is also worth noting that the definitions of the variable "figurative language" and "executive functioning" are too wide. For example, executive functioning are defined differently in various articles; some of which include language fluency Kave (2006) and others exclude it and only account for working memory and planning (Sesma et al., 2009). Therefore, in future research it may be possible to examine the correlation between figurative language comprehension and the level of executive functioning, taking into account the components of the various definitions.

It is also worth noting that many researches deal with the neurological aspect involved in figurative language comprehension (Mashal, Faust, Hendler \& Jung-Beeman, 2007; Stringaris, Medford, Giora, Giampietro, Brammer \& David, Ingerith \& Skye, 2003; Muller, Simion, 2006) and the neurological aspect involved in executive functioning (Ingerith \& Skye, 2003; Muller, Simion, Reviriego, Galera, Mazaux, Barat, \& Joseph, 2010). In future research it may be possible to examine the neurological connection between areas of the brain associated with executive functioning and areas of the brain associated with figurative language comprehension and see whether an overlap exists. It may also be possible to examine whether a deficiency in executive functioning or pragmatic language can predict a damaged area in the brain or vice versa. 
In conclusion, the findings of this research contribute to and expand the theoretical knowledge that exists about the characteristics of executive functioning and pragmatic abilities among children with learning disabilities and children with no learning disabilities. The results of the research indicate that children with learning disabilities experience significant difficulties with executive functioning and figurative language comprehension compared to children with no learning disabilities.

\section{Pedagogical Implications}

The findings of the research may contribute to a deeper understanding of the needs of children with difficulties in reading comprehension.

The educational counselor may be able to assist by setting an intervention policy that is necessary for this student population, and guide various institutional agents within the educational system and outside of it on how to implement and apply it. The main goal of intervention as a change agent would be the development of executive functioning and figurative language proficiency, while bolstering the use of aural and pictorial metaphors via modular coaching and corrective instruction.

The development of these competencies may contribute to improvement in planning ability, mental flexibility, working memory and the establishment of fluency, accuracy and self monitoring. Also to reinforcing the ability to understand and produce metaphors and strengthen creative and abstract thinking faculties.

Schools can identify difficulties with reading and the educational counselor's role will be to refer to assessment agents that specialize in this area to determine the level of difficulties and set a proper course for intervention.

Improvement in the executive functioning and language proficiency among the population of students experiencing difficulty with reading may lead to a significant improvement in their overall academic performance and as result, ease their adjustment with additional aspects such as personal, emotional, and social life situations.

By supporting in that way, the educational counselor would have fulfilled her role as a leading agent of the growth processes that fit the unique needs of students with reading difficulties.

The educational team of each school becomes essential. It has to act to improve the level of executive functioning using deductive tools among the general student population including the students with learning disabilities. Examples are: planning, organization, use of learning strategies, flexibility in thinking and the memorization of details; improving their figurative language comprehension skills in different areas of language use such as terminology, idioms and sentences. Acquiring these proficiencies may aid students better adjust to school and society at large and experience an adequate ability to learn and accomplish academically. It may also naturally lead to improved level of motivation to learn and strengthen the willpower to advance.

\section{References}

Ackerman, B. P. (1982). On comprehending idioms: do children get the picture? Journal of Experimental Child Psychology, 33(3), 439-454. http://dx.doi.org/10.1016/0022-0965(82)90058-3

Anderson, V., \& Catroppa, C. (2005). Recovery of executive skills following paediatric traumatic brain injury (TBI): A 2 year follow-up. Brain Injury, 19(6), 459-470. http://dx.doi.org/10.1080/02699050400004823

Berkeley, S., Bender, W. N., Peaster, L. G., \& Saunders, L. (2009). Implementation of Response to Intervention. Journal of Learning Disabilities, 42(1), 85-95. http://dx.doi.org/10.1177/0022219408326214

Birch, H. G. (1981). Neuropsychological aspects of brain dysfunction in children. In P. Black (Ed.), Brain dysfunction in children: Etiology, diagnosis and management (pp. 193-291). New York: Raven Press.

Champagne-Lavau, M., \& Joanette, Y. (2009). Pragmatics, theory of mind and executive functions after a right-hemisphere lesion: Different patterns of deficits. Journal of Neurolinguistics, 22(5), 413-426. http://dx.doi.org/10.1016/j.jneuroling.2009.02.002

Champagne-Lavau, M., \& Stip, E. (2010). Pragmatic and executive dysfunction in schizophrenia. Journal of Neurolinguistics, 23(3), 285-296. http://dx.doi.org/10.1016/j.jneuroling.2009.08.009

Cutting, L., Materek, A., Cole, C., Levine, T., \& Mahone, E. (2009). Effects of fluency, oral language, and executive function on reading comprehension performance. Annals of Dyslexia, 59(1), 34-54. http://dx.doi.org/10.1007/s11881-009-0022-0

De Jong, C. G. W., Van De Voorde, S., Roeyers, H., Raymaekers, R., Allen, A. J., Knijff, S., \& Rodriques-Pereira, R. 
(2009). Differential effects of atomoxetine on executive functioning and lexical decision in attention-deficit/ hyperactivity disorder and reading disorder. Journal of Child and Adolescent Psychopharmacology, 19(6), 699-707. http://dx.doi.org/10.1089/cap.2009.0029

Denckla, M. B. (1994). Measurement of executive function. In G. R. Lyon (Ed.), Frames of Reference for the Assessment of Learning Disabilities: New Views on Measurement Issues. Baltimore, MD: Paul H. Brookes Publishing Co.

DSM - Diagnostic and Statistical Manual of Mental Disorders (1994; 2000; 2013). Washington, DC: American Psychiatric Association.

Geurts, H. M., Broeders, M., \& Nieuwland, M. S. (2009). Thinking outside the executive functions box: Theory of mind and pragmatic abilities in attention deficit/hyperactivity disorder. European Journal of Developmental Psychology, 7(1), 135-151. http://dx.doi.org/10.1080/17405620902906965

Glantz, Y. (2010). Abstract Verbal Thinking Test. Ramat Gan: Bar Ilan University.

Gooch, D., Snowling, M., \& Hulme, C. (2011). Time perception, phonological skills and executive function in children with dyslexia and/or ADHD symptoms. Journal of Child Psychology and Psychiatry, 52(2), 195-203. http://dx.doi.org/10.1111/j.1469-7610.2010.02312.x

Gross-Tsur, V., Shalev, R., Manor, O., \& Amir, N. (1995). Developmental right-hemisphere syndrome: clinical spectrum of the nonverbal learning disability. Journal of Learning Disabilities, 28(2), 80. http://dx.doi.org/10.1177/002221949502800202

Hadad (2010). Assessment Kit for Adults. Ramat Gan: Bar Ilan University.

Johnson, D. J., \& Myklebust, H. R. (1967). Learning Disabilities; Educational Principles and Practices. New York: Grune \& Stratton.

Kasper, G. (1997). Can pragmatic competence be taught. NetWork, 6, 1-12.

Kavale, K. A., \& Forness, S. R. (1996). Social skill deficits and learning disabilities: A meta-analysis. Journal of Learning Disabilities, 29(3), 226. http://dx.doi.org/10.1177/002221949602900301

Kavé, G. (2006). The development of naming and word fluency: evidence from Hebrew-speaking children between ages 8 and 17. Developmental Neuropsychology, 29(3), 493. http://dx.doi.org/10.1207/s15326942dn2903_7

Kavé, G., Avraham, A., Kukulansky-Segal, D., \& Herzberg, O. (2007). How does the homophone meaning generation test associate with the phonemic and semantic fluency tests? A quantitative and qualitative analysis. Journal of the International Neuropsychological Society, 13(03), 424-432. http://dx.doi.org/10.1017/S1355617707070622

Kirk, S. A. (1963). Behavioral diagnosis and remediation of learning disabilitiesProceedings of the Annual Meeting of the Conference of Exploration into the Problems of Perceptually Handicapped Child (Vol. 1). Chicago.

Kogan, N., Connor, K., Gross, A., \& Fava, D. (1980). Understanding visual metaphor: Developmental and individual differences. Monographs of the Society for Research in Child Development, 1-78. http://dx.doi.org/10.2307/1165832

Lee, R. F., \& Kamhi, A. G. (1990). Metaphoric competence in children with learning disabilities. Journal of Learning Disabilities, 23(8), 476. http://dx.doi.org/10.1177/002221949002300805

Levorato, M. C., Nesi, B., \& Cacciari, C. (2004). Reading comprehension and understanding idiomatic expressions: A developmental study. Brain and Language, 91(3), 303-314. http://dx.doi.org/10.1016/j.bandl.2004.04.002

Martin, I., \& McDonald, S. (2003). Weak coherence, no theory of mind, or executive dysfunction? Solving the puzzle of pragmatic language disorders. Brain and Language, 85(3), 451-466. http://dx.doi.org/10.1016/S0093-934X(03)00070-1

Martindale, C. (1999). Biological Basis of Creativity. In R. J. Sternberg (Ed.), Handbook of creativity (pp. 137). Cambridge: Cambridge University Press.

Mashal, N. (2005). Cerebral processing of metaphoric language: a functional imaging study. Ramat-Gan: Bar-Ilan University. http://dx.doi.org/10.1016/j.bandl.2005.10.005

Mashal, N., Faust, M., Hendler, T., \& Jung-Beeman, M. (2007). An fMRI investigation of the neural correlates underlying the processing of novel metaphoric expressions. Brain and Language, 100(2), 115-126. 
Mayes, S. D., Calhoun, S. L., \& Crowell, E. W. (2000). Learning disabilities and ADHD. Journal of Learning Disabilities, 33(5), 417. http://dx.doi.org/10.1177/002221940003300502

Ministry of Education, General Manager Memo (1996). Learning Disabilities. Jerusalem: Publication Department, Ministry of Education.

Ministry of Education, General Manager Memo (2004). Learning Disabilities. Jerusalem: Publication Department, Ministry of Education.

Monetten, S., Bigras, M., \& Guay, M.-C. (2011). The role of the executive functions in school achievement at the end of Grade 1. Journal of Experimental Child Psychology, 109(2), 158-173. http://dx.doi.org/10.1016/j.jecp.2011.01.008

Muller, F., Simion, A., Reviriego, E., Galera, C., Mazaux, J.-M., Barat, M., \& Joseph, P. A. (2010). Exploring theory of mind after severe traumatic brain injury. Cortex, 46(9), 1088-1099. http://dx.doi.org/10.1016/j.cortex.2009.08.014

Nippold, M. A. (1988). Later language development: ages 9 through 19: Little Brown and Company.

NJCLD - National Joint Committee on Learning Disabilities (1994; 2005). Washington, D.C: WETA.

Owens, R. E. (1992). Language development: an introduction (3rd ed.). New York: Macmillan Publishing Company.

Perner, J., \& Lang, B. (1999). Development of theory of mind and executive control. Trends in Cognitive Sciences, 3(9), 337-344. http://dx.doi.org/10.1016/S1364-6613(99)01362-5

Reiter, A., Tucha, O., \& Lange, K. W. (2005). Executive functions in children with dyslexia. Dyslexia, 11(2), 116-131. http://dx.doi.org/10.1002/dys.289

Rourke, B. P. (1988). Socioemotional disturbances of learning disabled children. Journal of Consulting and Clinical Psychology, 56(6), 801. http://dx.doi.org/10.1037/0022-006X.56.6.801

Rourke, B. P., \& Del Dotto, J. E. (1994). Learning disabilities: A neuropsychological perspective: Sage Publications, Inc.

Seidenberg, P. L., \& Bernstein, D. K. (1986). The Comprehension of Similes and Metaphors by Learning Disabled and Nonlearning-Disabled Children. Language, Speech, and Hearing Services in Schools, 17(3), 219. http://dx.doi.org/10.1044/0161-1461.1703.219

Seidman, L. J., Biederman, J., Monuteaux, M. C., Doyle, A. E., \& Faraone, S. V. (2001). Learning disabilities and executive dysfunction in boys with attention-deficit/hyperactivity disorder. Neuropsychology, 15(4), 544. http://dx.doi.org/10.1037/0894-4105.15.4.544

Sesma, H. W., Mahone, E. M., Levine, T., Eason, S. H., \& Cutting, L. E. (2009). The Contribution of Executive Skills to Reading Comprehension. Child Neuropsychology, 15(3), 232-246. http://dx.doi.org/10.1080/09297040802220029

Spector, C. C. (1990). Linguistic humor comprehension of normal and language-impaired adolescents. Journal of Speech and Hearing Disorders, 55(3), 533. http://dx.doi.org/10.1044/jshd.5503.533

Spector, C. C. (1996). Children's Comprehension of Idioms in the Context of Humor. Language, Speech, and Hearing Services in Schools, 27(4), 307.

Stone, C., \& May, A. L. (2002). The accuracy of academic self-evaluations in adolescents with learning disabilities. Journal of Learning Disabilities, 35(4), 370. http://dx.doi.org/10.1177/00222194020350040801

Stringaris, A. K., Medford, N., Giora, R., Giampietro, V. C., Brammer, M. J., \& David, A. S. (2006). How metaphors influence semantic relatedness judgments: The role of the right frontal cortex. NeuroImage, 33(2), 784-793. http://dx.doi.org/10.1016/j.neuroimage.2006.06.057

Tannocck, R. (2013). Specific learning disabilities in DSM-5; Are the changees for better or worse? The International Journal for Research in Learning Disabilities, 1(2), 2-30.

Yang, F. G., Fuller, J., Khodaparast, N., \& Krawczyk, D. C. (2010). Figurative language processing after traumatic brain injury in adults: A preliminary study. Neuropsychologia, 48(7), 1923-1929. http://dx.doi.org/10.1016/j.neuropsychologia.2010.03.011 


\section{Notes}

Note 1. In the Hebrew language, visual punctuation is a set of signs used in addition to vowels as indicators to the correct pronunciation of words.

Note 2. The Theory of Mind is a specific cognitive ability to understand others as intentional agents, in other words, to interpret their opinion in theoretical terms of intentional states, ours and theirs: what do we know, think, want, feel etc. (Perner \& Lang, 1999). 